\title{
RANCANGAN SISTEM APLIKASI PEMBAYARAN SPP BERBASIS WEBSITE DENGAN MENGGUNAKAN METODE FRAMEWORK Yii (Studi Kasus di SDS Mulya Asri Kab. Tangerang)
}

\author{
Danang Rifai ${ }^{1}$ \\ Sendy Zul Friandi ${ }^{2}$ \\ Taufan Aditya Pratama ${ }^{3}$

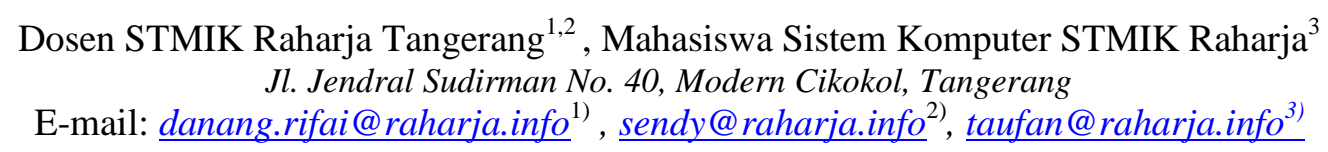

ABSTRAK

SDS Mulya Asri Kabupaten Tangerang saat ini memerlukan system aplikasi pengolahan data pembayaran SPP yang baik terstruktur dan terpadu guna memudahkan dalam pengambilan keputusan dan menciptakan standar komputerisasi Keuangan Sekolah Dasar yang di targetkan oleh pemerintah daerah.Data Sistem informasi yang mudah di oprasikan oleh staff tata usaha sekolah dibutuhkan guna mendukung kinerja dari staff tata usaha. Pada pengolahan data Sistem Aplikasi di SDS Mulya Asri masih di rasakan kurang sempurna di karenakan masih ada yang menggunakan catatan manual buku besar, dimana dalam pengolahan database keuangan masih berkendala hilangnya buku keuangan dan data ganda sehingga data pembayaran SPP tidak terintregrasi. Penelitian ini dibuat melalui tahap (1) Identification, yaitu mengindentifikasi Masalah, (2) Understand, yaitu memahami kerja dari system yang ada di lokasi penelitian, (3) Analyst, yaitu menganalisisa system yang berjalan, (4) Report, yaitu membuat laporan hasil analisa.Fungsi utama dari aplikasi pembayaran ini yaitu untuk memudahkan pengolahan data pembayaran SPP secara cepat, terintergrasi, dan terkomputerisasi.

Kata Kunci: Sistem, Aplikasi, Pembayaran, Sekolah Dasar

\section{ABSTRACT}

SDS Mulya Asri Tangerang Regency currently requires a data processing application system of SPP payment is well structured and integrated in order to facilitate decision-making and create computerized standard of Primary School Finance targeted by local government. Data Information systems that are easy to operate by the school administration staff needed to support the performance of administrative staff. In the data processing System Application in SDS Mulya Asri still in less perfect in because there are still using manual record ledger, where in the processing of financial database is still constrained loss of financial books and double data so that SPP payment data is not integrated. This research is done through stage (1) Identification, that is identifying Problem, (2) Understand, that understand work from system exist in research location, (3) Analyst, that is analyze system running, (4) Report, analysis. The main function of this payment application is to facilitate the processing of SPP payment data quickly, integrated, and computerized.

Keywords: System, Application, Payments, Primary School 


\section{PENDAHULUAN}

Komputer sebagai peralatan pemecahan masalah, dan dapat juga disebut sebagai alat pengolah data. Pada saat ini teknologi sudah berkembang pesat dengan adanya komputer yang bukan hanya sebagai pengolahan data tetapi juga bisa menampilkan informasi. Perkembangan teknologi informasi membuat hidup manusia menjadi mudah, terutama sejak diciptakannya jaringan internet, komunikasi menjadi semakin tidak terbatas dan tanpa hambatan. Pada Penelit ian ini akan membahas tentang sistem pembayaran pada sebuah Sekolah Dasar Swasta Mullya Asri Kab. Tangerang, yang dimana sistem pembayaran dan rekap SPP masih menggunakan Buku Besar dan MS. Office. maka diperlukan pengembangan dalam input biaya serta mengolah laporan pembayaran SPP pada sekolah dasar Mullya Asri, Dengan adanya sistem informasi pembayaran berbasis website yang di dukung dengan Framework Yii diharapkan ke seluruhan sistem pembayaran SPP yang ada di SDS Mullya Asri dapat teratasi lebih efektif dan efisien. Sistem pembayaran termasuk salah satu kegiatan administrasi khususnya proses pengolahan biaya pendidikan.

\section{PERUMUSAN MASALAH}

Pengolahan data pembayaran SPP di SDS Mullya Asri dirasakan masih kurang efektif karena sistem yang adad belum terkomputerisasi dengan baik walaupun sudah menggunakan komputer sebagai alat bantu. Program aplikasi yang di gunakan masih mengunakan MS. Office untuk mencetak surat tanda terima pembayaran. Dengan ini penulis menjabarkan rumasan masalah antara lain yaitu :

1. Dengan melihat sistem yang berjalan, apakah perlu dirancangnya suatu sistem aplikasi pembayaran SPP pada SDS Mullya Asri Kab. Tangerang?

2. Media Aplikasi seperti apakah yang dibutukan oleh user SDS Mullya Asri?

\section{LITERATUR REVIEW}

Literature review adalah suatu survey literature tentang penemuan-penemuan yang telah dilakukan oleh penelitian sebelumnya yang berhubungan dengan topik penelitian.

a. Penelitian yang telah dilakukan oleh Puji Yurnaningsih (2011)

Penelitian ini berjudul "Perancangan Sistem Informasi Pembayaran Spp menggunakan Aplikasi VB. 6.0 Pada Digikids", pada tahun 2011. metode yang diusulkan pada penelitian ini menggunkan program Visual Basic 6.0. Program yang dibuat masih harus dilakukan evaluasi agar tidak terjadi kesalahan-kesalahan dalam peng-inputan data absensi dan agar tidak terjadi kehilangan data.

b. Penelitian yang telah dilakukan oleh Ma'mun Murod (2015)

Penelitian ini berjudul "Perancangan Sistem Aplikasi Kasir Online Pada SMIP Gemagawita ", pada tahun 2015. Metode yang diusulkan pada penelitian ini menggunakan program Macromedia Dreameaver MX dengan My SQL. Memberikan usulan kepada Sekolah SMIP Gemagawita tentang sistem kasir online yang telah dikembangkan agar lebih mudah digunakan secara efektif dan efisien serta ingin mengetahui lebih jauh tentang sistem-sistem yang sedang berjalan yang berkenaan dengan Kasir tersebut..

c. Penelitian yang telah dilakukan oleh Tri Novita Sari (2011)

Penelitian ini berjudul "Perancangan Sistem Informasi pembayaran SPP berbasis website pada SMK PGRI 1". Korelasi dengan spenelitian ini adalah masalah yang dihadapinya dari sistem ini adalah, Pada penelitian sebelumnya menjelaskan tentang masalah yamg dihadapi dari sistem yang ditelitinya di tempat tersebut. Karena di tempat tersebut untuk melayani Siswa dalam pembayaran spp masih bersifat manual dan penyimpanan data terlalu lama dari sistem yang sekarang berjalan di tempat tersebut.

d. Penelitian yang dilakukan oleh Dwi Astuti (2015)

Penelitian ini tentang "Perancangan Sistem Komputerisasi Peminjaman dan Pengembalian Buku Pada Perpustakaan Umum Cikokol Tangerang".Sistem ini dibuat untuk mempermudah dalam penyimpanan data-data perpustakaan yang penting, dikarenakan pencatatannya masih menggunakan buku dan lemari arsip sehingga 
kemungkinan hilang dan rusaknya data sangat besar.Maka dibuat suatu sistem dengan menggunakan Visual Basic. Kesamaan yang terdapat dalam penelitian yang dilakukan oleh penulis yaitu terdapat pada Tujuan dari pembuatan sistem informasi yang lebih baik dalam proses penyimpanan data-data, pencatatan data-data, serta meminimalkan terjadinya kemungkinan data yang hilang.

e. Penelitian yang dilakukan oleh Rudy Hartanto (2010)

"Perancangan Sistem Pengendalian Dokumen ISO TS 16949 Pada Departement R\&D Automotive di PT IRC INOAC Indonesia PU Division".Hubungan dengan penelitian yang penulis lakukan adalah dari aspek dasar dilakukannya penelitian yaitu untuk membuat sistem dokumen yang lebih baik dari yang sudah ada.

\section{METODE PENELITIAN}

Metode penelitian suatu proses pengumpulan dan analisis data yang dilakukan secara sistematis, untuk mencapai tujuan-tujuan tertentu. Pengumpulan dan analisis data dilakukan secara ilmiah, baik bersifat kuantitatif maupun kualitatif, eksperimental maupun non eksperimental, interaktif maupun non interaktif, "Nana Syaodih Sukmadinata, Metode Penelitian Pendidikan, (Bandung: Rosda Karya, 2012), hal. 5"

Adapun dalam penelitian ini menggunakan Metode Penelitian Sebagai Berikut :

1. Metode Pengumpulan Data

Metode pengumpulan data ada tiga tahap yang harus di lakukan diantaranya yaitu, Observasi, Wawancara, serta Studi Pustaka.

2. Metode Analisa dan Perancangan SistemWatterfall

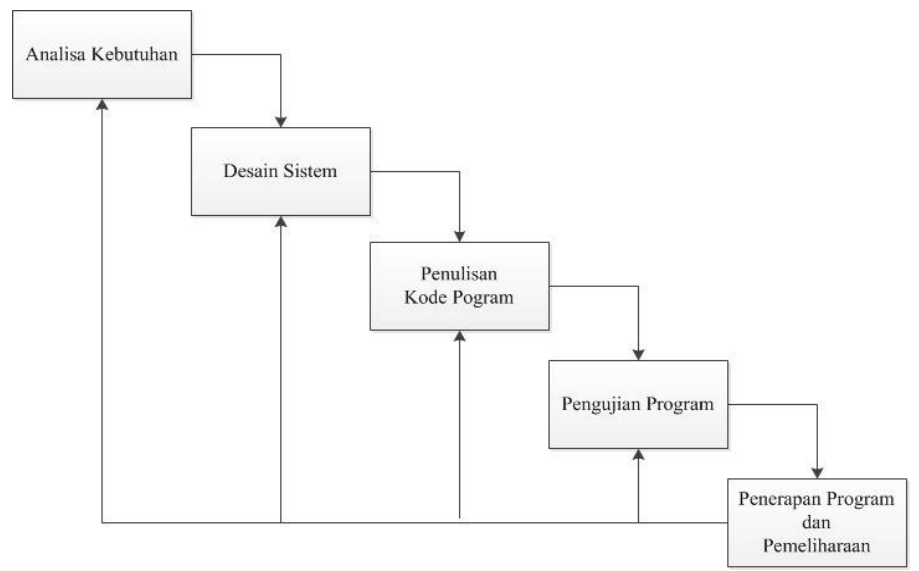

Gambar 1. Teori Metode Analisa Dan Perancangan Watterfall

Metode Analisa Sistem dengan menggunakan analisis Watterfall.Secara garis besar metode waterfall mempunyai langkah-langkah sebagai berikut : Analisa, Desain, Penulisan, Pengujian dan Penerapan serta Pemeliharaan. (Kadir, 2010)

Tahapan Metode Waterfall:

\section{a. Analisa Kebutuhan}

Langkah ini merupakan analisa terhadap kebutuhan sistem.

b. Desain Sistem

Tahapan dimana dilakukan penuangan pikiran dan perancangan sistem terhadap solusi dari permasalahan yang ada dengan menggunakan perangkat pemodelan sistem seperti diagram alir data (data flow diagram), diagram hubungan entitas (entity relationship diagram) serta struktur dan bahasan data.

c. Penulisan Kode Program

Penulisan kode program atau coding merupakan penerjemahan design dalam bahasa yang bisa dikenali oleh komputer. Dilakukan oleh programmer yang akan meterjemahkan transaksi yang diminta oleh user.Tahapan ini lah yang merupakan tahapan secara nyata dalam mengerjakan suatu sistem. 


\section{d. Pengujian Program}

Tahapan akhir dimana sistem yang baru diuji kemampuan dan keefektifannya sehingga didapatkan kekurangan dan kelemahan sistem yang kemudian dilakukan pengkajian ulang dan perbaikan terhadap aplikasi menjadi lebih baik dan sempurna.

e. Penerapan Program dan Pemeliharaan

Perangkat lunak yang sudah disampaikan kepada pelanggan pasti akan mengalami perubahan. Perubahan tersebut bisa karena mengalami kesalahan karena perangkat lunak harus menyesuaikan dengan lingkungan (periperal atau sistem operasi baru) baru, atau karena pelanggan membutuhkan perkembangan fungsional.

\section{TEORI KHUSUS}

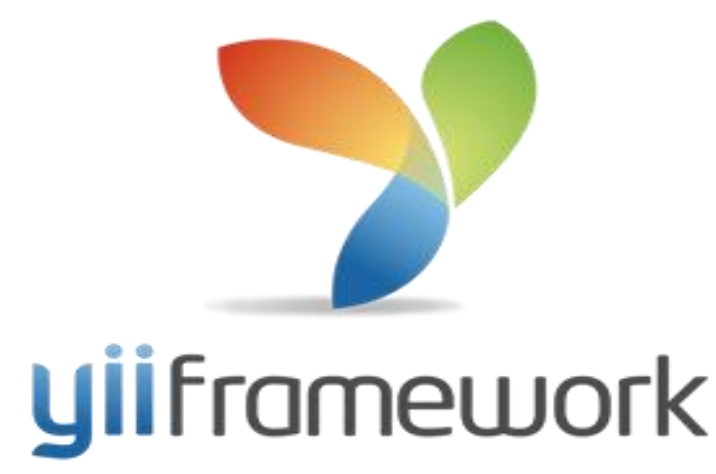

Gambar 2. Bahasa Pemrograman Menggunakan Yii Framework

Yiiadalah kerangka kerja (Framework) open source berbasis php. Nama Yii (dieja sebagai /i:/) singkatan dari "Yes It Is!".Seperti juga Framewor PHP pada umumnya, Yii juga telah mengadopsi

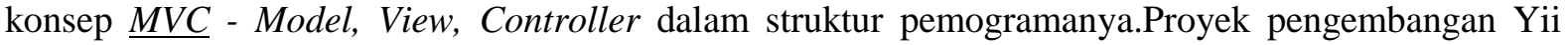
dimulai sejak 1 Januari 2008 oleh Qiang Xue programer asal Tiongkok.Pada awalnya Yii dikembangkan menggunakan bahasa kerja $\underline{P R A D O}$ framework, setelah mengalami beberapa koreksi dan penyempurnaan kurang lebih setahun, pada 3 Desember 2008, Yii 1.0 secara resmi dirilis ke publik.

Sumber : http://www.yiiframework.com/doc/guide/1.0/id/quickstart.what-is-yii

\section{DESAIN ALUR SISTEM USULAN}

\section{Use Case Diagram}

Diagram use case digunakan untuk memperlihatkan hubungan antara actor case yang ada dalam sistem. Sehingga calon pengguna sistem mendapatkan pemahaman tentang sistem yang akan di rancang. 


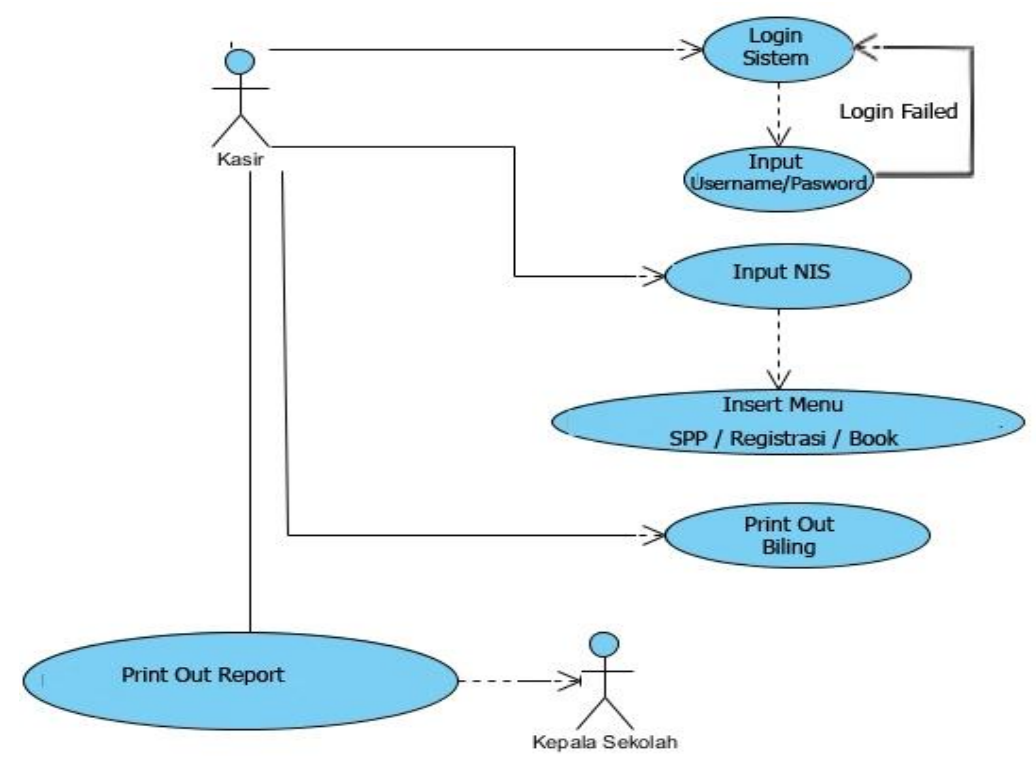

Gambar 3. Use Case Diagram Proses Pembayaran SPP

Pada gambar diatas menerangkan kegiatan Kasir Tata Usaha selaku pengguna sistem dalam penginputan biaya SPP. Yang dapat langsung Report ke Kepala Sekolah.

\section{Activity Diagram}

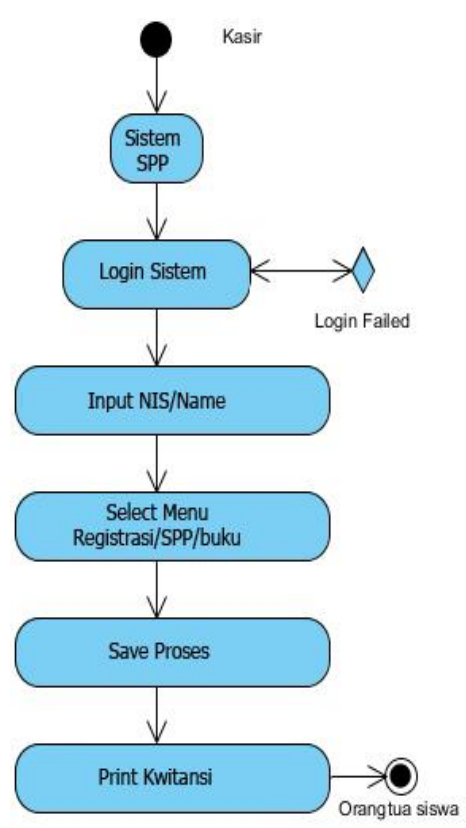

Gambar 4. Activity DiagramProses Pembayaran SPP

Activity diagram menggambarkan berbagai alur aktifitas dalam sistem yang di rancang, pada gambar diatas menjabarkan tentang alur proses mulainya input biaya pembayaran SPP sampai berakhir pada pencetakan kwitansi yang nantinya akan diberikan kepada orang tua siswa. 


\section{Class Diagram}

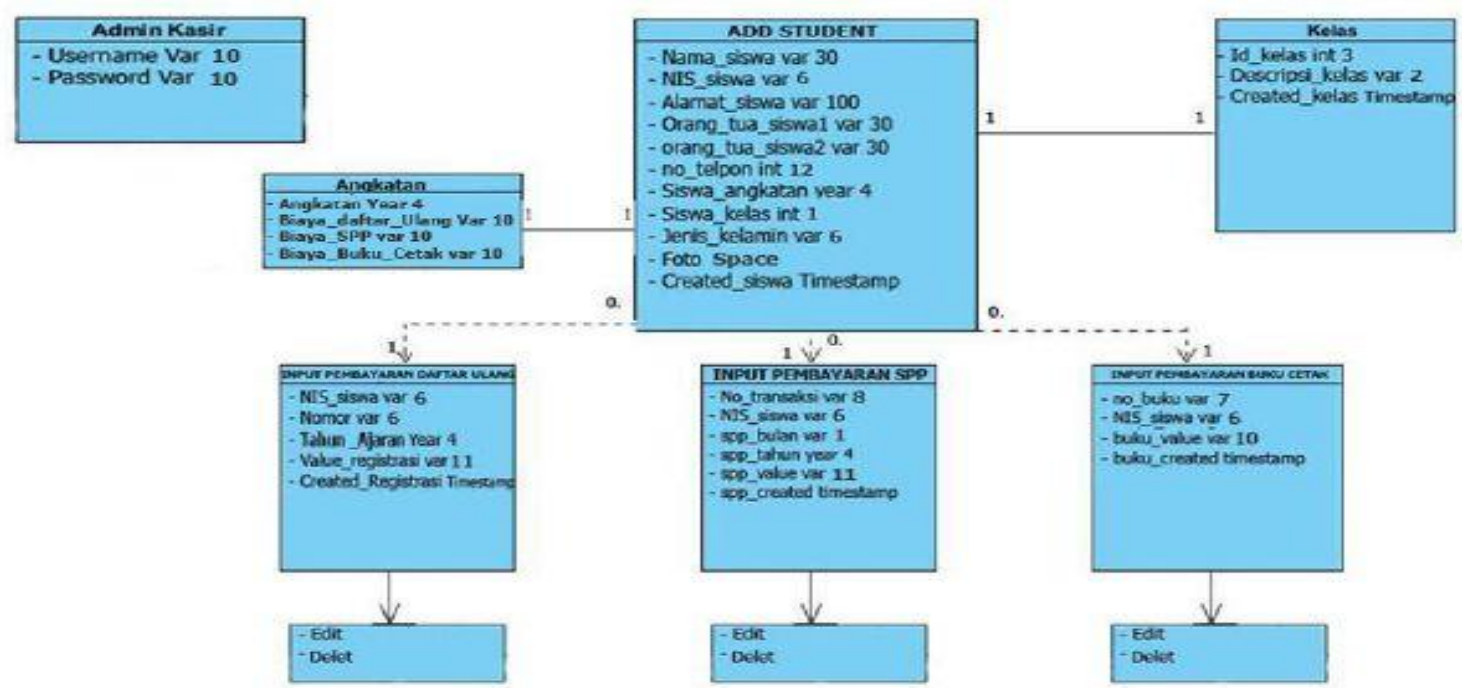

Gambar 5.Class Diagram Yang diusulkan

Keterangan: 1 ke 1 adalah one to one

0 ke 1 adalah many to one

1 ke 0 adalah one to many

Pada gambar diatas ada 6 class, Himpunan dari objek-objek yang berbagi atribut serta operasi yang sama. Keterangan pertama 1 siswa memiliki 1 kelas, Keterangan kedua banyak siswa yang melakukan 1 kali pembayaran registrasi di setiap semester, Keterangan ketiga banyak siswa yang melakukuan 1 kali pembayaran buku di setiap semester. Keterangan keempat banyak siswa yang melakukan 1 kali pembayaran spp di setiap semester dan yang terakhir Admin memiliki hak untuk membuat data baru, menghapus dan merubah data.

\section{IMPLEMENTASI SISTEM APLIKASI}

\section{TampilanSorcecode yii framework}

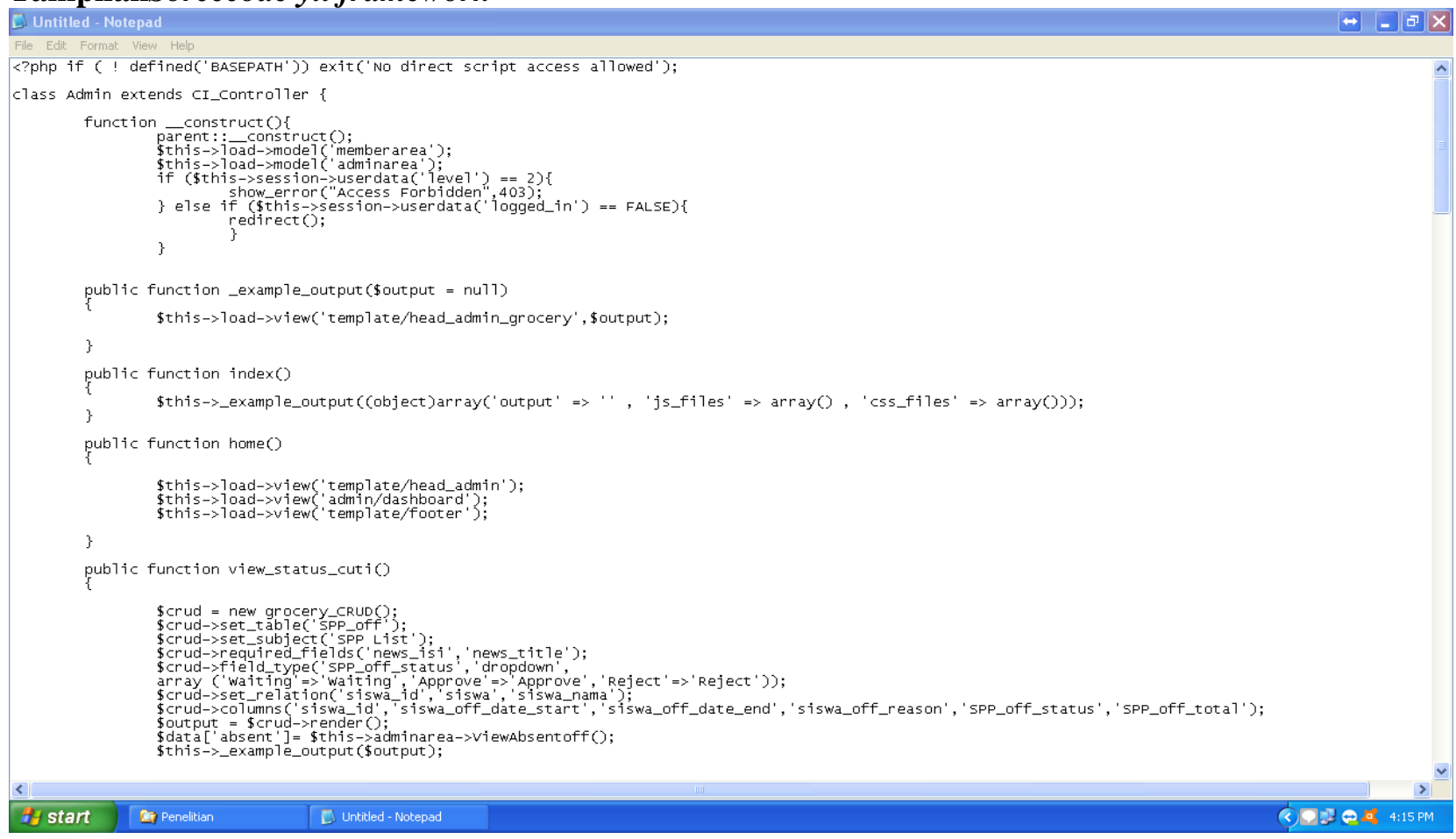


Gambar 6. Sorcecode yii framework

Dari kondisi yang terjadi sesuai dengan gambar diatas, maka dapat disimpulkan bahwa sistem akan berjalan dengan baik bila seorang Sistem Devlover merancang seitem dengan listing program yang baik dan benar.

\section{Tampilan Menu login}

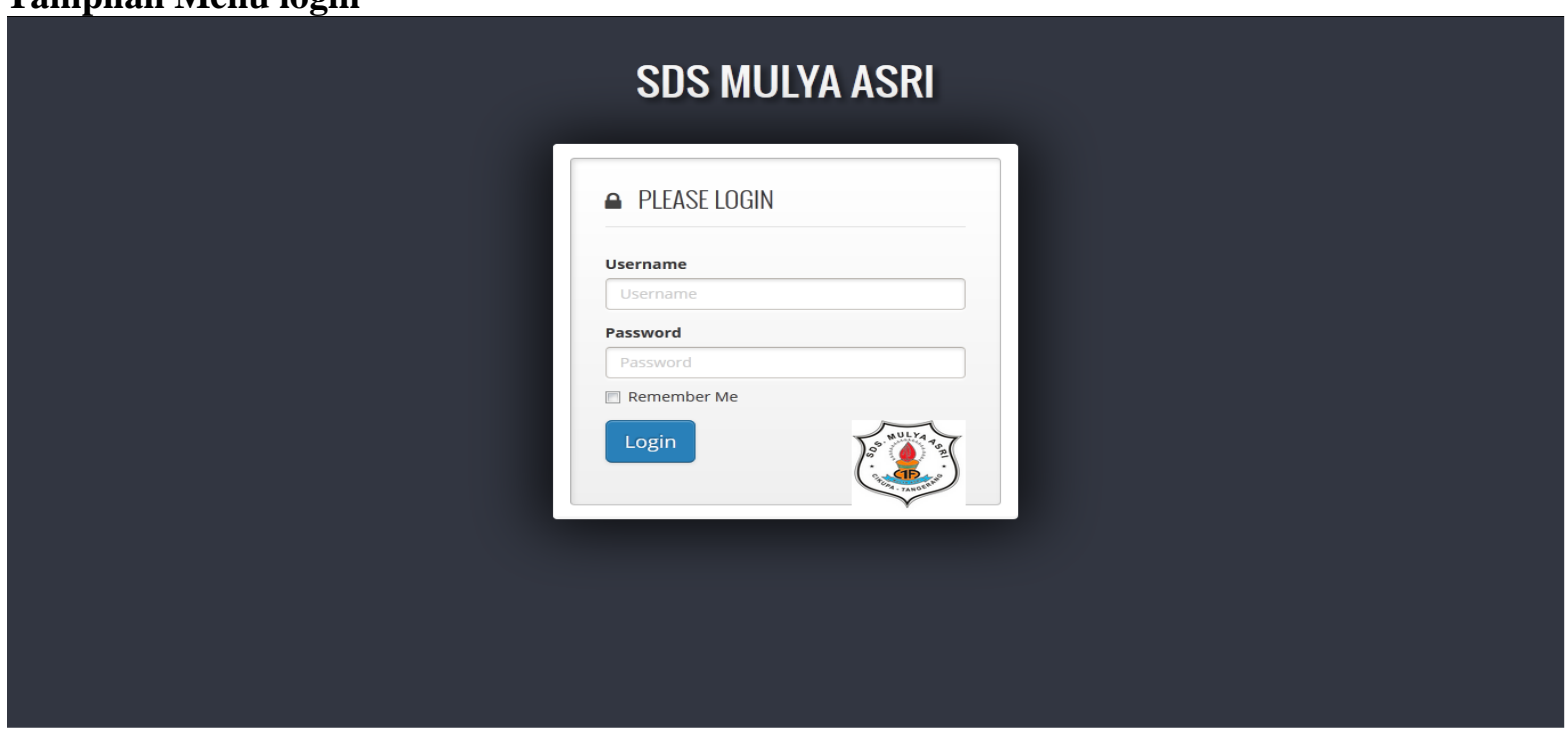

Gambar 7. Login Sistem

Pada gambar diatas menampilkan halaman utama login. Kegunaan menu login tersebut agar tidak sembarangan orang dapat mengakses atau menggunakan sistem pembayaran SPP. Yang dapat mengkases program ini adalah Kasir Sekolah dan Pimpinan Sekolah yang telah memiliki username dan password

\section{Tampilan Menu Dashboard}

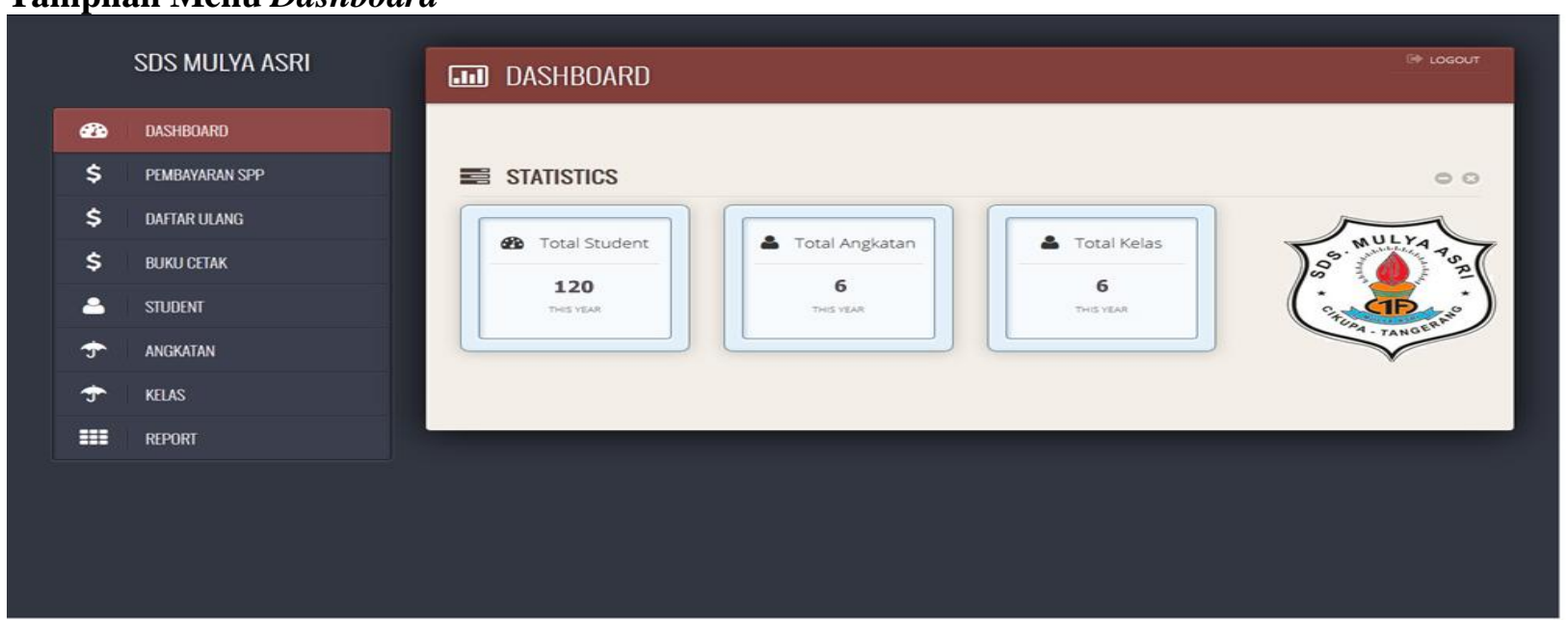

Gambar 8.Dashboard

Pada gambar diatas dimana user yang telah login akan otomatis masuk kedalam dashboard, pada dashboard terdapat beberapa pilihan menu yaitu, Pembayaran SPP, Pembayaran Daftar Ulang, Pembayaran Buku, Daftar Siswa, Daftar Angkatan, Daftar Kelas, dan terakhir adalah Report. 


\section{Tampilan Menu Pengelola Data}
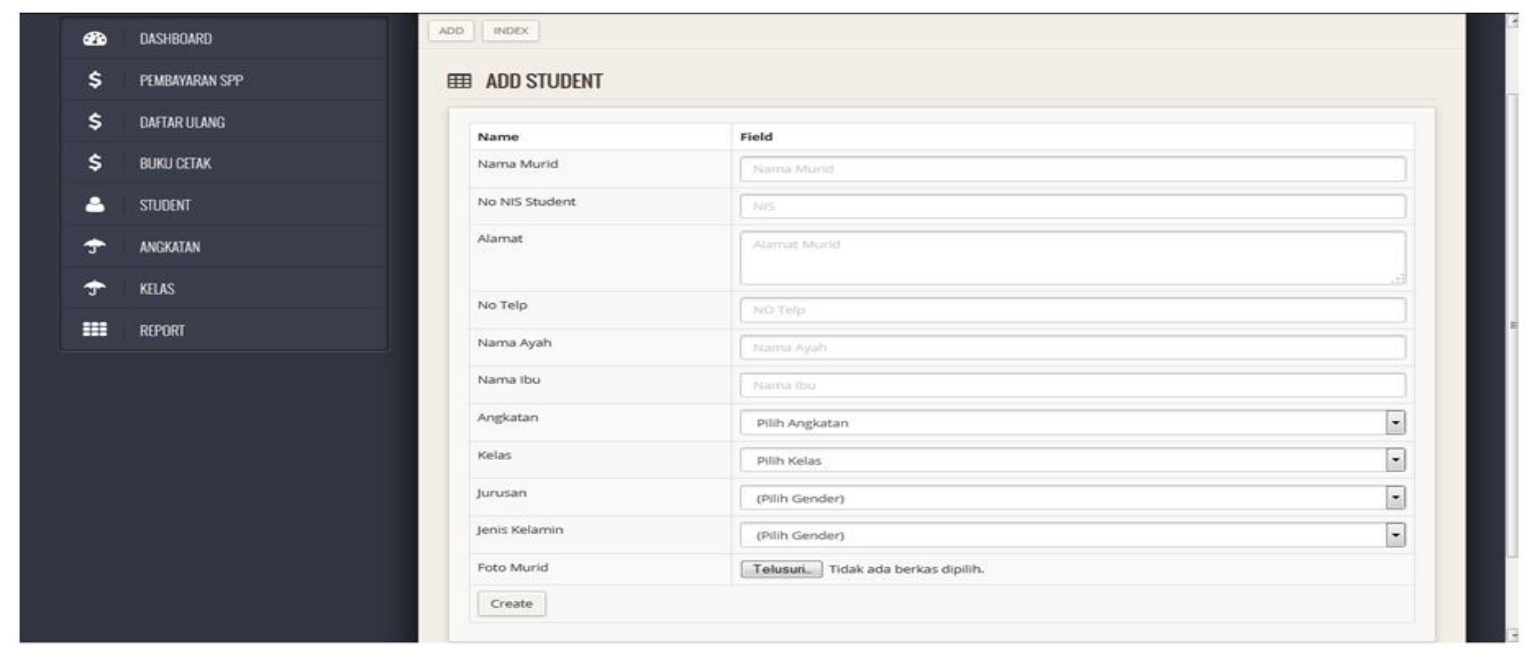

Gambar 9. Pengelolaan Data

Pada gambar diatas menjelaskan jika admin yaitu kasir sekolah dapat mengelola data siswa yakni mengedit data, menambah data, dan menghapus data.

\section{Tampilan Menu Pembayaran}
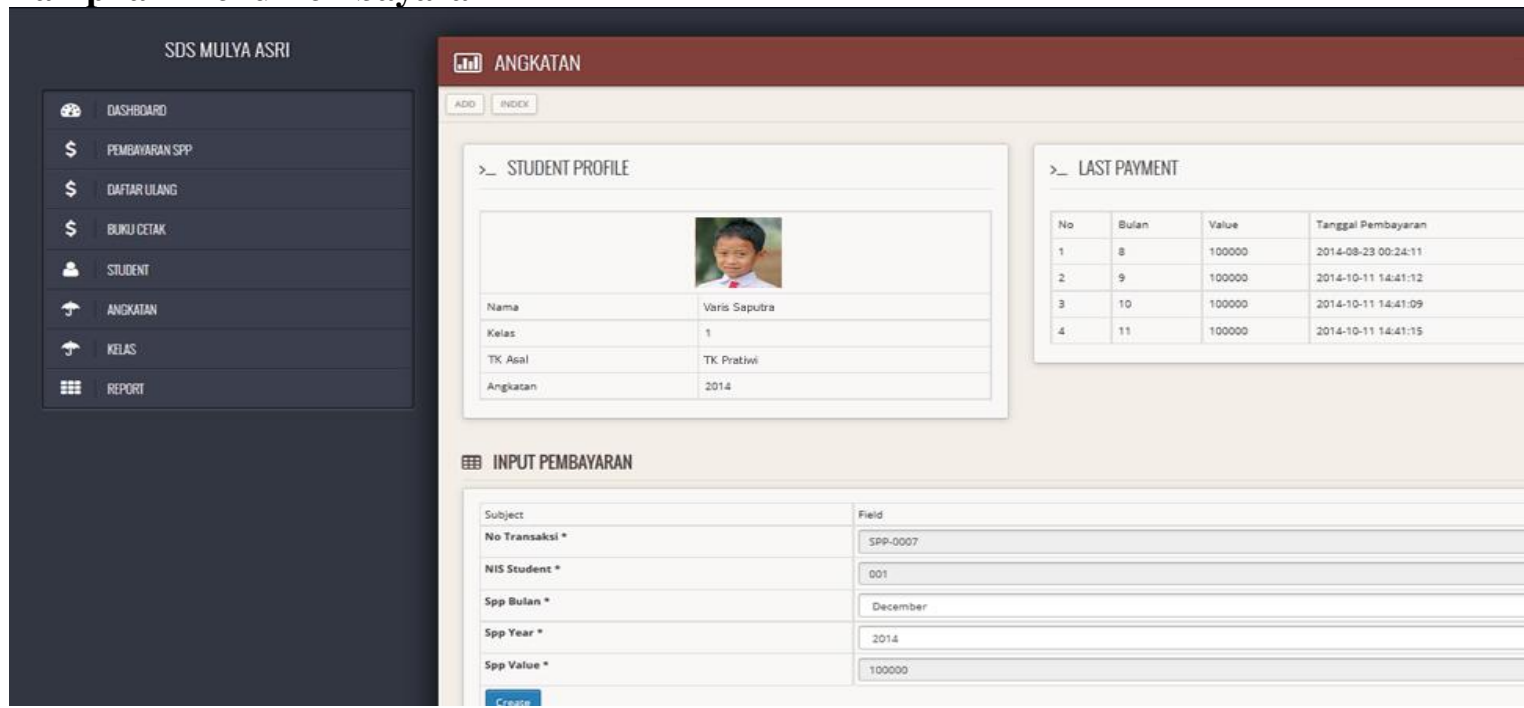

Gambar 10. Proses Pembayaran

Gambar 9 diatas menjelaskan tentang penginputan data pembayaran SPP setelah transaksi pembayaran di input maka akan terlihat pula history pembayaran SPP sebelumnya. Dimana siswa akan terdeteksi telah melakuan pembayaran SPP atau masih menunggak pembayaran SPP. 


\section{Tampilan Cetak Kwitansi Pembayaran}

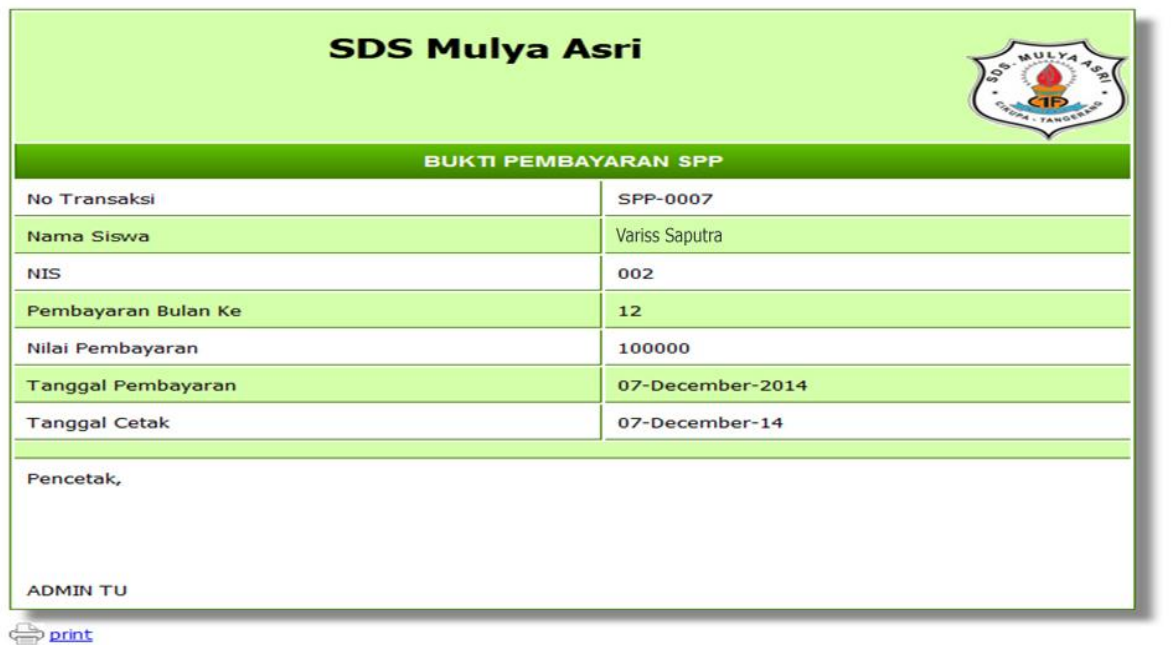

\section{Gambar 11. Proses Cetak Kwitansi}

Pada gambar 10 diatas menjelaskan jika proses pembayaran SPP selesai di lakukan maka tahap selanjutnya adalah pencetakan kwitansi atau tanda bukti pembayaran untuk orang tua siswa. Gambar di atas adalah tampilan sistem kwitansi sebelum di print out.

\section{Tampilan Menu Laporan}

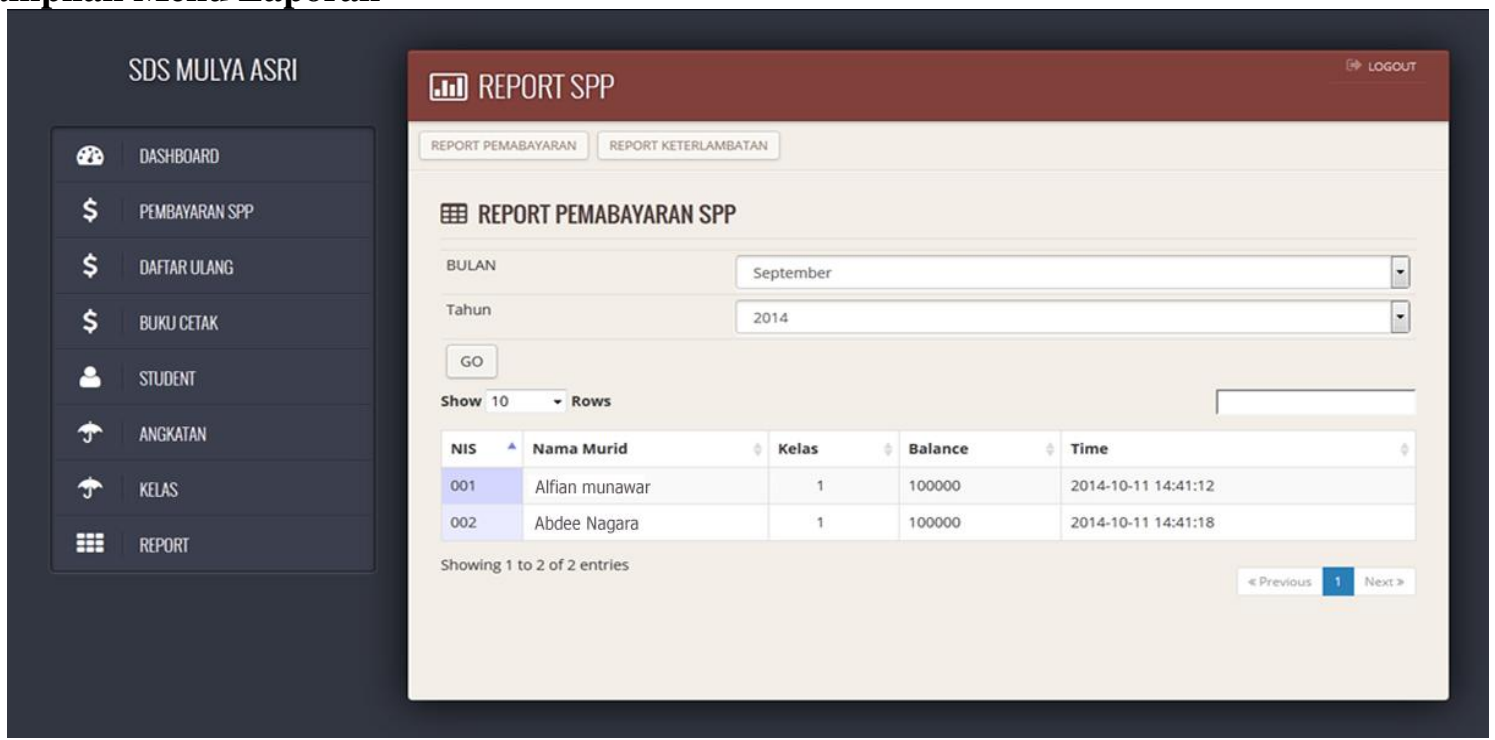

Gambar 12. Report

Setiap transaksi pembayaran sekolah SPP, Daftar ulang, dan Buku tentulah harus diberikan laporan kepada kepala sekolah di setiap transaksinya.Agar terciptanya transparansi biaya pemasukan Sekolah.Dan pada gambar 11 diatas menampilkan halaman Report untuk di akses oleh Kepala Sekolah SDS Mullya Asri.

\section{KESIMPULAN}

Berdasarkan hasil pembahasan yang telah diuraikan pada penelitian diatasdan hasil pengamatan penulis dari rumusan masalah, maka dapat diambil kesimpulan sebagai berikut: 
1. Sistem pelayanan pembayaran spp siswa masih dilakukan secara manual dan belum menggunakan sistem aplikasi yang baik. Maka perlu adanya sistem aplikasi berbentuk Website untuk melayani pembayaran SPP pada SDS Mullya Arsi.

2. Dengan merancang sistem aplikasi pelayanan kasir berbentuk website, maka pelayanan pembayaran SPP terhadap orang tua siswa menjadi efektif secara komputerisasi. Dan demikian maka SDS Mullya Arsi menjadi Sekolah Dasar yang Berstandar Pelayanan dengan Sistem Komputer di Kabupaten Tangerang

\section{SARAN}

Bagi peneliti berikutnya yang akan melakukan penelitian dengan topik sejenis disarankan hendaknya untuk menambahkan jumlah sampel yang digunakan. Mengembangkan kembali sistem yang masih berkendala $(B U G)$, dan memperbaharui kembali listing program yang dinyatakan telah usang.

\section{DAFTAR PUSTAKA}

[1] Kamil H. 2013. Pengembangan Aplikasi Distribusi Fakultas Teknologi Informasi Dengan Notifikasi SMS Menggunakan Framework Yii dan GAMMU.

[2] Arry Budi W, dkk. 2014. Perancangan SIS+ Menggunakan Metode Yii Framework Pada Perguruan Tinggi Raharja.CCIT vol 8. No 2 Perguruan Tinggi Raharja.

[3] Nusron. 2013 Aplikasi Counter Mikrokontroler Untuk Menghitung Penonton Dipintu Masuk Stadion dengan Sensor PING LED. Jurnal Teknika Vol XXXII Desember 2013

[4] Untung Rahardja 2012 "Definsi iLearning”. Raharja Entichmen Centre (REC) Tangerang

[5] Yii Framework ( di akses pada 19 Juli 2017 ) Definisi "yii framework" tersedia di http://www.yiiframework.com/doc/guide/l.0/id/quickstart.what-is-yii

[6] Sovia dkk. 2013 Membangun Aplikasi e-Library Menggunakan HTML, PHP Script dan MYSQL Database.Jakarta ; Jurnal Teknologi Informasi dan Pendidikan. Vol 3No 1Maret 2013 ISSN ; 208$\underline{4981}$

[7] Larman. C. 2012 Applying UML and patterns : And Introduction to Object Orientied Analysis Design dan Interactive Depelovment. Pearson Education India

[8] Abdul Kadir. 2010. Analisa dan Perancangan Sistem, Jakarta. 2010

[9] Nana Syaodih Sukmadinata, Metode Penelitian Pendidikan, (Bandung: Rosda Karya, 2012), hal. 5 